University of Nebraska - Lincoln

DigitalCommons@University of Nebraska - Lincoln

Faculty Publications, Department of Psychology

Psychology, Department of

May 2003

\title{
Parent-Adolescent Communication About Sex: Retrospective Reports by Latino College Students
}

\author{
Marcela Raffaelli \\ University of Nebraska-Lincoln, mraffaelli1@unl.edu \\ Stephanie Green \\ University of Nebraska-Lincoln
}

Follow this and additional works at: https://digitalcommons.unl.edu/psychfacpub

Part of the Psychiatry and Psychology Commons

Raffaelli, Marcela and Green, Stephanie, "Parent-Adolescent Communication About Sex: Retrospective Reports by Latino College Students" (2003). Faculty Publications, Department of Psychology. 83. https://digitalcommons.unl.edu/psychfacpub/83

This Article is brought to you for free and open access by the Psychology, Department of at DigitalCommons@University of Nebraska - Lincoln. It has been accepted for inclusion in Faculty Publications, Department of Psychology by an authorized administrator of DigitalCommons@University of Nebraska - Lincoln. 
Published in Journal of Marriage and Family 65 (May 2003), pp. 474-481.

Copyright (C) 2003 by the National Council on Family Relations. http://www.ncfr.org

Published by Blackwell Publishing, Inc. Used by permission.

"The definitive version is online at http://www.blackwell-synergy.com/"

\title{
Parent-Adolescent Communication About Sex: Retrospective Reports by Latino College Students
}

\author{
Marcela Raffaelli and Stephanie Green \\ Department of Psychology and Institute for Ethnic Studies \\ University of Nebraska-Lincoln
}

\begin{abstract}
Latina female $(n=97)$ and Latino male $(n=69)$ college students $(M$ age $=21.4$ years) completed self-report surveys regarding family of origin experiences, including sexual communication with parents while growing up. Latino parents of this comparatively highly educated sample tended to use direct rather than indirect strategies for communicating about sexuality with their children. Young women reported higher levels of sexual communication with mothers while growing up than did young men, and respondents reported less communication with fathers than mothers. Among young women, sexual communication with mother was positively associated with non-Mexican origin and negatively associated with having older brothers living at home. In contrast, maternal education was positively associated with mother-son communication about sex. Paternal education and the absence of older brothers positively predicted communication with both sons and daughters. The analyses provide novel information regarding sexual communication in Latino families and suggest directions for future research.
\end{abstract}

Key Words: Latino families, parent-child communication, sexuality.

The issue of how to promote responsible sexuality among American youth has moved to the forefront of the nation's attention (Satcher, 2001). After decades of research, it is clear that there are no simple solutions: adolescent sexuality has been linked to personality, biological, demographic, social, and cultural influences. At the same time, scholars emphasize the key role of parents as primary agents of sexual socialization (Katchadourian, 1990). Much of the research on how parents affect adolescent sexual behavior has focused on communication, examining parents' explicit attempts to transmit values and share information (Miller, Benson, \& Galbraith, 2001). This body of research reinforces the role of parent-child communication in shaping adolescent sexual attitudes and behavior. At the same time, much remains to be learned about how parents communicate with their children about sexual issues, particularly in ethnically diverse families.

Latinos (individuals of Latin American origin or descent living in the U.S.) currently make up $13 \%$ of the U.S. population but are expected to comprise one quarter of the population by the Year 2050. Unplanned pregnancies and sexually transmitted infections pose considerable risk to Latino teens (Child Trends, 2001). Because Latinos have been understudied relative to other U.S. ethnic groups (McLoyd, Cauce, Takeuchi, \& Wilson, 2000), including in the area of sexual communication (O'Sullivan, Jamarillo, Moreau, \& Meyer-Bahlburg, 1999), limited information is available for scholars and practitioners working to address issues of teen pregnancy and sexually transmitted infections among Latino populations.

Parent-child communication about sexuality has been linked to Latino adolescents' attitudes and behavior. In several studies, pregnant Latina teens re- 
ported lower levels of sexual communication with parents than did non-pregnant teens (Adolph, Ramos, Linton, \& Grimes, 1995; Baumeister, Flores, \& Marin, 1995). Thus, family communication may be an important factor to consider in risk reduction efforts with Latino populations. Prior research, however, suggests that Latino parents are less likely to communicate with their adolescents about sexual issues than parents from other ethnic groups (e.g., Hovell et al., 1994). In telephone surveys with 1,600 unmarried 18- to 49-year-old Latinos in 10 states, half of the respondents said their parents had never talked to them about sex (Marin \& Gomez, 1997). Smaller-scale studies (most including only female participants) also reveal low levels of discussions regarding sexual topics in Latino families (Baumeister et al., 1995; Raffaelli \& Ontai, 2001). It has been suggested that Latino parents may prefer to use indirect communication strategies, such as making comments to other people in the child's hearing or telling children to "be careful" without going into details (Marin \& Gomez; Villaruel, 1998). At present, however, little systematic information is available regarding the topics that Latino parents discuss with their children or preferred strategies for communicating sexual information.

The goal of the current analysis was to extend current understanding of sexual communication in Latino families. The analysis was guided by theory and prior research. Across numerous studies conducted with Latinos as well as non-Latinos, parent and child gender have emerged as major influences on parentchild communication about sexual issues. Traditional Hispanic culture is marked by differential treatment of male and female children (Castaneda, 1996), particularly in the areas of gender and sexuality (for reviews, see Espin, 1984/1997; Raffaelli \& Suarez-alAdam, 1998). In non-Latino families, mothers engage in more sexuality-related communication than fathers, and daughters report more communication than sons (e.g., Dilorio, Kelley, \& Hockenberry-Eaton, 1999; Raffaelli, Bogenschneider, \& Flood, 1998). In contrast, it has been proposed that a traditional cultural emphasis on female innocence may make Latino parents reluctant to discuss sexuality with daughters (Marin \& Gomez, 1997). Prior research has revealed conflicting findings. In an observational study of Latino teens and their mothers, mother-son dyads spent more time than mother-daughter dyads talking about sex (Romo, Lefkowitz, Sigman, \& Au, 2001); in con- trast, Latina adolescents self-reported higher levels of communication about sex with their mothers than did their male peers (Hovell et al., 1994).

A variety of other demographic factors have been found to be associated with whether parents and adolescents communicate about sex (although little of this research has included Latino families). In general, non-Latino parents are more apt to talk to their children about sex when they are of higher socioeconomic status (Hovell et al., 1994; Hutchinson \& Cooney, 1998). In contrast, Latina mothers from lower income families reported higher levels of communication about sex than those from higher income families (Romo et al., 2001). Thus, the potential role of socioeconomic status is unknown. Other family factors that may be linked to communication about sexuality include the presence of older siblings in the home (e.g., Hofstetter et al., 1995). Finally, cultural variables such as acculturation level and national origin may also play a role in sexual socialization in Latino families (Driscoll, Biggs, Brindis, \& Yankah, 2001).

Drawing on this literature, we examined parent-adolescent communication about sex in a sample of Latino young adults attending college. This sample represents a unique opportunity for exploring this topic because it is comparable to the non-Latino samples studied in prior research on young adult recollections of parent-child communication (e.g., Fisher, 1988; Hutchinson \& Cooney, 1998; Lehr, Dilorio, Dudley, $\&$ Lipana, 2000). Because theory and research have emphasized the influence of gender on parent-child communication, parent and child gender were a major focus of the analyses.

\section{Method}

\section{Procedures and Participants}

Respondents were drawn from a larger study (conducted in 1999-2000) targeting Latino students at four postsecondary institutions in a mid-western state (two state universities, one community college, and one private university). With the cooperation of each institution's registration office, survey packets and reminder postcards were sent to all currently enrolled students identified as Latino/Hispanic in registration records. Depending on the institution, respondents either received $\$ 10$ and were entered into a drawing for an additional bonus payment, or were paid $\$ 15$. 
The exact number of students who were eligible to participate is unknown. Survey packets were directmailed by each institution to protect student privacy; the investigator did not have access to any identifying or demographic information. At three institutions it was not possible to restrict the mailing to students in the larger study's target age range (19-45) so the mailing was sent to all Latino students, who were instructed to discard the survey if they were not eligible to participate. Surveys were mailed to 871 individuals; 26 surveys were either undeliverable or recipients informed the investigator that they were ineligible. Of the remaining 845 surveys, 242 (28.6\%) were returned. Response rates ranged from $23.5 \%$ at the community college to $33 \%$ at the private university. Recruitment site differences were assessed by examining group differences in outcomes and demographic variables. Community college students reported significantly lower levels of parent education than students from the other three institutions. No differences were found in sexual communication, age, family language, or parental country of origin.

The analysis sample was limited to respondents aged 25 and under $(n=166)$, on the basis of several considerations. First, most respondents $(69 \%)$ were 25 or younger. Second, restricting the sample was one way of limiting problems associated with retrospective recall bias. Finally, past research examining family of origin experiences among college students has focused on this age range (e.g.. Fisher, 1988; Lehr et al., 2000; Lopez \& Hamilton, 1997). The analysis sample included 97 female and 69 male students ( $M$ age $=21.4$ years $)$. Most respondents were unmarried (92\%), Catholic (71\%), and had been born in the U.S. (84\%). When asked to select the ethnic term(s) that best described them, $42 \%$ chose Hispanic/Latino, 28\% chose Mexican American, and the remainder Mexican (8\%), Puerto Rican (4\%), or another term (e.g., Chicano, Cuban, 17\%).

\section{Measures}

Direct communication about sexual issues. Respondents indicated the number of times they had discussed 19 different sexuality-related topics with each parent "while growing up (before age 16)" on a fivepoint scale: 1 (never), 2 (7-2 times), 3 (3-5 times), 4 (6-10 times), 5 (more than 10 times). A direct communication index was created for each parent by averaging scores on the 19 items $(\alpha=.93$ for both moth- ers and fathers). In addition, for each parent four subscales reflecting different areas of communication were created: relationships (e.g., appropriate age to start dating, boyfriends or girlfriends; 5-item $\alpha=.85$ for mothers, .84 for fathers); sexual/acts (e.g., pregnancy, menstruation; 3 -item $\alpha=.82$ for mothers, .77 for fathers); protection (e.g., birth control, prevention of sexually transmitted infections; 7-item $\alpha=.93$ for mothers, .91 for fathers); and values (e.g., religious beliefs about premarital sex; 4-item $\alpha=.78$ for mothers, .82 for fathers). The sexual communication items were drawn from a previously created measure (Raffaelli et al., 1999) that was modified on the basis of a pilot study (Raffaelli \& Ontai, 2001). Similar measures have been used in research with college students (e.g.. Fisher, 1988; Lehr et al., 2000).

Indirect communication. Three items based on pilot research (Raffaelli \& Ontai, 2001) assessed the extent to which each parent used indirect strategies to convey sexual messages (e.g., "[My mother] would talk to other people about sexual issues when I was in the room"). Items were rated on the same 5-item response scale as for direct communication. Responses were averaged to form an overall score for each parent $(\alpha=$ .66 for mothers, .74 for fathers).

Cultural characteristics. Two cultural variables were included in the analyses. Language use while growing up with mother; father; brothers or sisters, or both; and other relatives was rated on a 5-point scale (1 = Spanish only, 2 = Spanish more than English, 3 = Both the same, $4=$ English more than Spanish, 5 $=$ English only). An overall family English use score was computed by averaging the four items, with a higher score indicating more English use $(\alpha==.95 ; M$ $=3.96, S D=1.34$ ). Aside from the U.S., parents originated from 19 different countries and grandparents from 24 different countries, with Mexico being the most common country of origin (other than the U.S.). A dichotomous non-Mexican origin item was computed for each parent; Mexican ancestry was coded as 0 (32.5\% of mothers, $37.3 \%$ of fathers) and non-Mexican ancestry was coded as 1 .

Parental education. Average number of years of education completed was 12.8 for mothers (range $=2-$ 17 ) and 13.0 for fathers (range $=0-17$ ).

Older siblings. Two dichotomous variables reflected whether older siblings were in the home while re- 
Table 1. Frequency of Sexual Communication by Respondent and Parent Gender

\begin{tabular}{|c|c|c|c|c|c|c|}
\hline & \multicolumn{2}{|c|}{ Mothers } & \multicolumn{2}{|c|}{ Fathers } & \multicolumn{2}{|c|}{ Mothers vs. Fathers } \\
\hline & Women & Men & Women & Men & Women & Men \\
\hline Direct communication & 2.67 & $2.19^{* * *}$ & 1.72 & 1.78 & *** & $* * *$ \\
\hline Indirect communication & 2.09 & 2.09 & 1.44 & $1.75^{*}$ & $* * *$ & ** \\
\hline \multicolumn{7}{|l|}{ Specific topics } \\
\hline Relationships & 3.46 & $2.91 * *$ & 2.32 & 2.36 & $* * *$ & $* * *$ \\
\hline Values & 2.77 & $2.13^{* * * *}$ & 1.99 & 1.69 & $* * *$ & $* * *$ \\
\hline Sexual facts & 2.70 & $1.86 * * *$ & 1.37 & 1.56 & $* * *$ & $* * *$ \\
\hline Protection & 2.09 & 1.94 & 1.34 & $1.62 *$ & $* * *$ & ** \\
\hline
\end{tabular}

Note: $N=97$ women, 69 men. Values represent mean frequency of discussion while respondent was growing up: $1=$ never, $3=3-5$ times, $5=$ more than 10 times,

${ }^{*} p<.05 .{ }^{* *} p<.01 .{ }^{* * *} p<.001$.

spondents were growing up $(31 \%$ had brothers, $28 \%$ sisters).

\section{Results}

\section{Patterns of Sexual Communication}

Differences in mean levels of sexual communication were examined by computing a repeated measures multivariate analysis of variance (MANOVA) with strategy (direct vs. indirect) and parent (mother vs. father) as within-subject factors and respondent gender as a between-subjects factor. Main effects emerged for strategy, $F(1,163)=15.20, p<.001$, and parent, $F(1,163)=113.94, p<.001$, but not gender, $F(1,163)=1.56, n s$. Participants reported more direct than indirect communication, and more communication with mothers than fathers. Interactions emerged between gender and strategy, $F(1,163)=5.26, p<$ 01 , strategy and parent, $F(1,163)=6.64, p<.05$, and gender and parent $F(1,163)=15.42, p<.001$. Means are displayed in Table 1. Follow-up tests revealed that young women reported significantly more direct than indirect communication with both mothers $(p<$ $.001)$ and fathers $(p<.001)$, whereas young men reported similar levels of direct and indirect communication with each parent. Young women reported more direct communication with mothers $(p<.001)$, and less indirect communication with fathers $(p<.05)$, than did young men.

Differences in frequency of discussion of specific topics were examined by computing separate repeated measures MANOVA for each parent. See Table 1 for means. In the analysis for mothers, there were main effects for gender, $F(1,164)=16.26, p<.001$, and topic, $F(3,162)=81.78, p<.001$, and a gender by topic interaction, $F(3,162)=8.71, p<.001$.
For fathers, there was a main effect for topic, $F(3$, $161)=88.58, p<.001$, and a gender by topic interaction, $F(3,161)=6.06, p<.001$, but no main effect for gender, $F(1,163)=0.04, n s$. Overall, relationships and values were more frequently discussed than protection and facts. Both young women and men reported higher levels of discussions with mothers than fathers. Young women discussed relationships, facts, and values with mothers more often than did young men, who in turn discussed protection with fathers more often than did young women.

\section{Predictors of Direct and Indirect Sexual Communication}

Relations between sexual communication and demographic factors and family characteristics (gender, non-Mexican origin, family English use, parent education, and presence of older brothers or sisters) were examined. In bivariate correlations, higher levels of direct communication with mothers were associated with female gender $(r=.25, p<.001)$ and maternal education $(r=.26, p<.001)$. Direct communication with fathers was associated with paternal education $(r$ $=.29, p<.001)$ and non-Mexican origin $(r=.28, p$ $<.001)$. There were no significant bivariate correlates for indirect communication with either parent.

Multiple linear regressions analyses were conducted to examine linkages between the predictors and direct and indirect communication with each parent. The predictor variables were entered simultaneously to examine their unique and combined effects. Because theory and past research emphasize the role of gender in parent-child sexual communication, interactions between gender and each predictor variable were also examined. Interactions were entered simultaneous- 
Table 2. Regressions on Direct Sexual Communication With Mothers and Fathers

\begin{tabular}{|c|c|c|c|}
\hline & \multicolumn{2}{|c|}{ Mothers } & \multirow{2}{*}{$\begin{array}{c}\text { Fathers } \\
\text { Model } 1\end{array}$} \\
\hline & Model 1 & Model 2 & \\
\hline Female gender & $.26^{* * *}$ & .21 & -.06 \\
\hline Parent education (years) & $.18^{*}$ & $.39 * *$ & $.20^{*}$ \\
\hline Parent non-Mexican origin & $.18^{*}$ & -.02 & $.21 *$ \\
\hline Family English use & -.12 & -.16 & -.11 \\
\hline Older brothers & $-.15 *$ & -.07 & $-.18^{*}$ \\
\hline Older sisters & .04 & .21 & .07 \\
\hline \multicolumn{4}{|l|}{ Gender $\times$} \\
\hline Parent education & - & $-.27 *$ & - \\
\hline Non-Mexican origin & - & .29 & - \\
\hline English language & - & .05 & - \\
\hline Older brothers & - & -.15 & - \\
\hline Older sisters & - & -.22 & - \\
\hline$R^{2}$ & $.19 * * *$ & $.24 * * * *$ & $.16^{* * * *}$ \\
\hline
\end{tabular}

$*_{n}<05 *_{n}<01 . * *_{n} *_{n}<.001$

ly on a separate step to see if additional explanatory power was gained. Interaction terms were computed by centering variables and multiplying by gender (dummy coded as $0=$ male, $1=$ female).

In the model for direct communication with mothers, the first step was significant, $F(6,157)=6.09, p$ $<.001$. As shown in Table 2, higher levels of direct communication about sex were reported by young women and respondents whose mothers had higher levels of education, whose mothers were of nonMexican origin or descent, or who did not have older brothers living at home while growing up. The gender interactions at the second step resulted in a close-tosignificant $R^{2}$ change, $\Delta R^{2}=.05, F_{\mathrm{ch}}=2.10, p=.069$. The final model was significant, $F(11,152)=4.39, p$ $<.001$, with maternal education remaining significant and a significant gender by maternal education interaction emerging. The direct effects model was computed separately for men and women to further examine this interaction (not shown). Maternal education was significantly associated with direct sexual communication for young men $(\beta=.42, p<.01)$ but not women $(\beta=.04, n s)$. Among young women, sexual communication with mother was positively associated with non-Mexican origin $(\beta=.25, p<.05)$ and negatively associated with having older brothers living at home $(\beta=-.24, p<.05)$.

In the model for direct communication with fathers, the first step was significant, $F(6,152)=4.66, p<$ .001 . Communication was positively associated with paternal education, non-Mexican origin, and the absence of older brothers (Table 2). The gender interac- tions at the second step did not result in a significant $R^{2}$ change; $\Delta R^{2}=.02, F_{\text {ch }}=0.71, n s$, so only the first model is presented.

Parallel analyses for indirect communication with mothers and fathers were conducted. Neither model was significant: mothers, $F(11,152)=0.79$, $n s$; fathers, $F(11,147)=1.0, n s$.

\section{Discussion}

Our goal was to extend current understanding of sexual communication in Latino families, drawing on retrospective reports by Latino college students. Although this sample is not representative of the general population of Latinos in the U.S., it is comparable to the samples studied in past research on this topic. Thus, the current study replicates and extends prior research on parent-child communication about sex, which has seldom included Latinos.

Consistent with prior research conducted with primarily non-Latino samples (Dilorio et al., 1999; Hutchinson \& Cooney, 1998; Raffaelli et al., 1998), gender was a primary influence on the extent of parent-child communication. In general, mothers were more likely than fathers to communicate with their children about sexual issues, and daughters reported higher levels of communication than sons. These findings add to literature suggesting that despite traditional cultural reticence regarding female sexuality in Hispanic cultures (e.g., Marin \& Gomez, 1997; Romo et al., 2001), among U.S. Latinos mother-daughter communication is more frequent than mother-son 
communication (Ho veil et aL, 1994). Heightened levels of communication may be the result of parental education; over half of the parents of respondents in the current study had at least some college education. Moreover, maternal education was positively associated with the extent to which sons reported talking to mothers about sex, and paternal education predicted communication with both sons and daughters.

Several other demographic factors were associated with the extent to which parents communicated directly with their children about sex. In regressions, parental national origin was associated with mother-daughter communication and with fathers' communication with both sons and daughters. Respondents whose parents were of Mexican origin reported less extensive communication about sexual issues than those whose parents were of non-Mexican origin, even after controlling for other demographic factors. This finding suggests that something unique to Mexican culture may be operating and highlights the importance of examining variations within ethnic subgroups (Castaneda, 1996; Parke, 2000). Another intriguing finding was that having older brothers (but not sisters) at home while growing up was associated with lower levels of sexual communication with both parents. This may reflect a constraining influence of male children on family communication regarding sexuality.

Examination of specific topics revealed that parents were more likely to discuss relationships and values as compared with sexual facts and protection. Studies with European American (Raffaelli et aL, 1998) and Latino (Baumeister et al., 1995; Raffaelli \& Ontai, 2001) populations also reveal that topics such as birth control and sexually transmitted infections are less frequently discussed, perhaps because they require specialized knowledge or may lead to discussions about the parent's or the child's behavior. On the basis of theorizing regarding cultural reticence surrounding sexuality, it was expected that Latino families might engage in high levels of indirect communication, conveying messages without having to initiate potentially embarrassing discussions. In fact, lower levels of indirect rather than direct communication were reported for all parent-child combinations except fathers and sons, and no significant associations were found between indirect communication and demographic and family characteristics. It may be that indirect communication is linked to factors not examined in the current analysis.
This study has a number of limitations that should be kept in mind when interpreting the findings. First, the sample is not representative of U.S. Latinos. In 1996, $57.5 \%$ of 18- to 24-year-old Hispanics had completed high school, and about a third of high school graduates attended college (Wilds \& Wilson, 1998). Respondents' parents were also more highly educated than the general Latino adult population; over half had at least some college education, compared to under a third of the general adult Latino population (U.S. Census Bureau, 2002). Another limitation is that retrospective reports may be biased by later experiences and memory distortions, although scholars maintain that family of origin experiences can be assessed retrospectively (e.g., Melchert $\&$ Sayger, 1998), and retrospective reports have been used to examine characteristics of Latino families (López \& Hamilton, 1997) and communication in European American and African American families (Fisher, 1988; Hutchinson \& Cooney, 1998; Lehr et al., 2000). Another limitation is that information does not reflect the viewpoint of parents, which may differ from that of their children (Raffaelli et al., 1999). Finally, we were unable to evaluate the effects of other factors that might be linked to sexual communication, including family structure, experiences of teen pregnancy, or parental attitudes and comfort discussing sexuality (Jaccard, Dittus, \& Gordon, 2000).

Despite these limitations, the current analysis builds on recent research about ethnically diverse families (McLoyd et al., 2000; Parke, 2000) by providing novel information about sexual communication in Latino families. Comparative research has consistently shown that Latino parents discuss sexual issues with their children less often than parents from other ethnic groups (e.g., Baumeister et al., 1995; Hofstetter et al., 1995; Hovell et al., 1994). These ethnic group differences are often attributed to aspects of traditional Hispanic culture that discourage open discussion about sexuality. The current findings suggest that this is probably an oversimplification; although the families of the Latino college students who participated in this study did not engage in extensive communication regarding factual aspects of sexuality, there was a fair amount of discussion about relationships and values. Moreover, markedly different patterns of parent-child communication emerged depending on parent and child gender, and several demographic characteristics appeared to play 
a role in sexual communication. Taken as a whole, the findings highlight the importance of conducting in-depth research on parent-child communication about sexuality in Latino families.

\section{Note}

This research was funded by grants to Marcela Raffaelli from the National Institutes of Mental Health (R03-MH57650) and the University of Nebraska Research Council, and by a University of Nebraska Undergraduate Creative and Research Experiences (UCARE) grant to Stephanie Green and Marcela Raffaelli. Research assistance was provided by Jennifer Crispo, Shanta Griffin, Jennifer Haase, Stephanie Hewitt, Sarah Kepple, Lynn Marcus, Nicole Miller, Lenna Ontai, Tammy Pfeifer, Katie Pickett, Julie Siepker, Kathryn Wilke, and Byron Zamboanga.

\section{REFERENCES}

Adolph, C., Ramos, D. E., Linton, K. L., \& Grimes, D. A. (1995). Pregnancy among Hispanic teenagers: Is good parental communication a deterrent? Contraception, 51, 303-306.

Baumeister, L. M., Flores, E., \& Marin, B. V. (1995). Sex information given to Latina adolescents by parents. Health Education Research, 10, 233-239.

Castaneda, D. (1996). Gender issues among Latinas. In J. C. Chrisler, C. Golden, \& P. D. Rozee (Eds.), Lectures on the psychology of women (pp. 167-181). New York: McGraw-Hill.

Child Trends. (2001). Trends among Hispanic children, youth, and families. Retrieved August 27, 2001, from www.childtrends.org/PDF/Hispanicfactsheet2.pdf

Dilorio, C., Kelley, M., \& Hockenberry-Eaton, M. (1999). Communication about sexual issues: Mothers, fathers, and friends. Journal of Adolescent Health, 24, 181-189.

Driscoll, A. K., Biggs, M. A., Brindis, C. D., \& Yankah, E. (2001). Adolescent Latino reproductive health: A review of the literature. Hispanic Journal of Behavioral Sciences, 23, 255-326.

Espin, O. M. (1997). Cultural and historical influences on sexuality in Hispanic/Latin women: Implications for psychotherapy. In E. Espin (Ed.), Latina realities: Essays on healing, migration, and sexuality (pp. 83-96). Boulder, CO: Westview. (Original work published 1984)
Fisher, T. D. (1988). The relationship between parentchild communication about sexuality and college students' sexual behavior and attitudes as a function of parental proximity. The Journal of Sex Research, 24, 305-311.

Hofstetter, C. R., Hovell, M. E, Myers, C. A., Blumberg, E., Sipan, C., Yuasa, T, \& Kreimer, S. (1995). Patterns of communication about AIDS among Hispanic and Anglo adolescents. American Journal of Preventive Medicine, 11, 231-237.

Hovell, M., Sipan, C., Blumberg, E., Atkins, C., Hofsteter, C. R., \& Kreimer, S. (1994). Family influences on Latino and Anglo adolescents' sexual behavior. Journal of Marriage and the Family, 56, 973-986.

Hutchinson, M. K., \& Cooney, T. M. (1998). Patterns of parent-teen sexual risk communication: Implications for intervention. Family Relations, 47, 185-194.

Jaccard, J., Dittus, P. J., \& Gordon, V. V. (2000). Parentteen communication about premarital sex: Factors associated with the extent of communication. Journal of Adolescent Research, 15, 187-208.

Katchadourian, H. (1990). Sexuality. In S. S. Feldman \& G. R. Elliott (Eds.), At the threshold: The developing adolescent (pp. 330-351). Cambridge, MA: Harvard University Press.

Lehr, S. T, Dilorio, C., Dudley, W. N., \& Lipana, J. A. (2000). The relationship between parent-adolescent communication and safer sex behaviors in college students. Journal of Family Nursing, 6, 180-196.

López, L. C., \& Hamilton, M. (1997). Comparison of the role of Mexican-American and Euro-American family members in the socialization of children. Psychological Reports, 80, 283-288.

Marin, B. V., \& Gomez, C. A. (1997). Latino culture and sex: Implications for HIV prevention. In J. Garcia \& M. Zea (Eds.), Psychological interventions and research with Latino populations (pp. 73-93). Boston, MA: Allyn \& Bacon.

McLoyd, V. C., Cauce, A. M., Takeuchi, D., \& Wilson, L. (2000). Marital processes and parental socialization in families of color: A decade review of research. Journal of Marriage and the Family, 62, 1070-1093.

Melchert, T. P., \& Sayger, T. V. (1998). The development of an instrument for measuring memories of family of origin characteristics. Educational and Psychological Measurement, 58, 99-118.

Miller, B. C., Benson, B., \& Galbraith, K. A. (2001). Family relationships and adolescent pregnancy risk: A research synthesis. Developmental Review, 21, 1-38. 
O’Sullivan, L. E, Jaramillo, B. M. S., Moreau, D., \& Meyer-Bahlburg, H. F. L. (1999). Mother-daughter communication about sexuality in a clinical sample of Hispanic adolescent girls. Hispanic Journal of Behavioral Sciences, 21, 447-469.

Parke, R. D. (2000). Beyond White and middle class: Cultural variations in families-Assessments, processes, and policies. Journal of Family Psychology, 14, 331-333.

Raffaelli, M., Bogenschneider, K., \& Flood, M. F. (1998). Parent-teen communication about sexual topics. Journal of Family Issues, 19, 316-334.

Raffaelli, M., \& Ontai, L. L. (2001). "She's 16 years old and there's boys calling over to the house": An exploratory study of sexual socialization in Latino families. Culture, Health, and Sexuality, 3, 295-310.

Raffaelli, M., Smart, L., Van Horn, S., Hohbein, A., Kline, J., \& Chan, W. L. (1999). Do mothers and teens disagree about sexual communication? A methodological reappraisal. Journal of Youth and Adolescence, 28, 395-402.

Raffaelli, M., \& Suarez-al-Adam, M. (1998). Reconsidering the HIV/AIDS prevention needs of Latino women in the United States. In N. L. Roth and L. K.
Fuller (Eds.), Women and AIDS: Negotiating safer practices, care, and representation (pp. 7-41). New York: Haworth.

Romo, L. E, Lefkowitz, E. S., Sigman, M., \& Au, T. K. (2001). Determinants of mother-adolescent communication about sex in Latino families. Adolescent and Family Health, 2, 72-82.

Satcher, D. (2001). Surgeon General's call to action to promote sexual health and responsible sexual behavior. Washington, DC: Office of the Surgeon General,

U.S. Census Bureau. (2002). American Factfinder, Table 1484, Sex by educational attainment for the population 25 years and over (Hispanic or Latino). Retrieved February 18, 2003, from http://factfinder.census.gov

Villaruel, A. M. (1998). Cultural influences on the sexual attitudes, beliefs, and norms of young Latina adolescents. Journal of the Society of Pediatric Nurses, 3, 69-79.

Wilds, D. J., \& Wilson, R. (1998). Minorities in higher education 1997-1998. Washington, DC: American Council on Education. 